\title{
La imagen en acción
}

Algunos alcances sobre la significación en el arte desde la semiótica diseursiva

\author{
Mihaela Radulescu \\ Departamento Académico de Arte
}

3 I arte propone imágenes como aventuras del conocimiento. Implica en sus recorridos desde la posición del " otro ", fascinado por la entrada en el laberinto de los sentidos que el imaginario del yo artístico propone. Debe encontrar o hacer surgir su propio camino para así participar en la generación de sentidos, penetrar la realidad instalada y llegar a las fuentes de su representación, en busca de la empatía o de la diferencia. Hasta llegar a ser parte de una acción que significa y comunica, que refiere e instala, que crea sus propias realidades: la acción de la imagen artistica. El encuentro con el arte, desde el sujeto interprete, se da en un espacio de interacciones, donde la configuración de signos concentra significados y seduce los sentidos. Nos interesa plantear, a continuación, algunas delimitaciones conceptuales que podrán permitir un acercamiento al proceso de la interpretación receptiva del objeto de arte.

1. El LABERINTO del SEMTido Entramos en eI mundo de los sentidos como en el Laberinto de Salomón, cruzando una serie de círculos concéntricos interrumpidos en determinados puntos por donde uno puede transitar, para adentrarse analíticamente en estos territorios en los cuales nace el sentido. La semiótica de la imagen permite al investigador trazar sus propios recorridos, a partir de un conjunto de sistematizaciones e interpretaciones de lo visible, para explorar el funcionamiento del sentido en sus varios contextos. Hay que imaginar los círculos girando, y los portales cambiando permanentemente de lugar. El recorrido se modifica en cada caso y modifica a quien lo emprende.

2. MODUS OPERANDI. El número de círculos varia según la complejidad que se persigue al construir la matriz del laberinto. La misma división no pasa de ser una hipotesis de trabajo aplicada a un fenómeno sumamente complejo de interacciones. Porque el mundo de los sentidos es prácticamente infinito, en permanente movimiento y transformación. El recorrido es un modus operandi cuyo rigor no debe crear falsas expectativas. 
3. El ARTE. Nos interesa investigar el funcionamiento de la imagen artística. El arte explora sistemáticamente la materia simbólica del imaginario humano. Construye en el acto imágenes de todo tipo, planas o volumétricas. estáticas o dinámicas, simples o complejas, que remiten, en última instancia, a cierta visión del mundo. Hace acción simbólica y acción comunicativa al mismo tiempo. Produce una "realidad" : un plurisigno que funciona como eje de la significación dinámica, cargada de valores, que se genera en torno a la realidad creada en el momento de la comunicación del mismo productor con su propia obra o del otro con la obra con la cual entra en contacto en determinadas condiciones. El fenómeno acepta varias lecturas. Hemos escogido la de la mirada interpretativa del otro.

4. LA MIRADA DEL OTRO. Ante una imagen artística uno ve y por tanto interpreta: una realidad referida directa o indirectamente; la construcción de la imagen; el estilo o las implicaciones culturales; los valores implícitos o explícitos; una visión simbólica del mundo. Consideremos estos territorios del sentido como otros tantos círculos por explorar.

5. LA REALIDAD REFERIDA. El entorno estálleno de cosas, que cada uno ve a su manera. Los momentos de percepción pertenecen, por otro lado, a determinada cultura, lo que es un factor integrador, antes de establecerse la diferencia con respecto a otra cultura. Las cosas están allí, latentes, en el espacio, en la sociedad, y toman forma cuando uno está preparado a darse cuenta. La obra Đes darse crenta des diálogo entre una conciencia y su entorno, es lenguaje y es discurspmanifiestode da capacidad de respuesta de la humanidad. Puede ser que, en algunos momentos y espacios, el creador se vuelva más atento con un aspecto de la realidad que con otros, ante "un llamado del tema " como lo llamaba Edouard Pignon, desarrollado a partir de cierto contexto para plantear el encuentro con las propias inquietudes del creador. Además, el entorno ingresa en la obra como un conjunto de sugestiones que la tradición cultural y el mundo físico proponen al creador y de las cuales éste dispone según su propia disposición de resistencia o pasividad. Por consiguiente, la creación refiere la realidad de muchas maneras: como punto de arranque; como intencionalidad natural de las sugestiones versus intencionalidad creadora; como formas experimentadas en el proceso o como formas instaladas en el momento final del proceso de configuración. Lo que la mirada del otro capta son estas últimas, las realidades instaladas en la imagen; a partir de ellas, puede interesarse por las otras maneras de referir el entorno. 
6. LA REALIDAD INSTALADA. En la organización de la imagen artística, la realidad instalada es el eje para la realización de la función global de la comunicación, es decir la transmisión de un saber sobre el mundo. Como se trata de una comunicación estética, es también un modo específico de apropiación del mundo (Y. Lotman), donde opera una representación reductora y parcial de la realidad referida pero, al mismo tiempo, con una énfasis particular en determinados valores de la misma. Es una modelización de la realidad que la representa a la vez que representa la proyección de la conciencia que la percibe. Es así como la imagen artística se hace transmisora de saberes vinculados con el modelo interior del mundo, generado por determinada conciencia y constituido en el marco de una visión comunitaria del mundo. Esto significa que, para la mirada del otro, no sólo se trata de un reconocimiento de las realidades representadas sino también de una posible interpretación de los saberes constitutivos y ,con éstos, de la intencionalidad de la imagen.

7. LA APROPIACIÓN DEL MUNDO. El acto de lectura de la imagen artística es lugar de procesos cognoscitivos y de reacciones afectivas. Los dos componentes se relacionan con la realidad instalada en la imagen. Los procesos cognoscitivos valoran la capacidad referencial de la realidad instalada y desarrollan la confrontación subyacente entre el modelo artístico y el objeto modelizado, fijándose en las diferencias, las cuales, además de abrir una perspectiva sobre el punto de vista internalizado en la imagen, conllevan ante la comprobación del carácter creàdor de ficciones de la imagen. Esta es definida como artística, reconociéndose el saber hacer propio del arte: una técnica, una normativa, un lenguaje. Las reacciones afectivas funcionan de manera opuesta: en vez de proceder a un distanciamiento para razonar sobre la diferencia, la mirada del otro hace acto de identificación afectiva con el modelo propuesto de realidad, entablando en este nivel un diálogo fluido con la conciencia que lo ha generado y experimentando en el acto el placer de la simpatía o de la empatía. Se da la transferencia, a su propia conciencia, de las vivencias de la obra, ya transformadas en modos de ver y valores del punto de vista, por lo cual hace - a su vez - acto de apropiación del mundo representado. Pero, para que este proceso se realice, la realidad instalada debe presentar una estructura formal cuyos signos sean reconocidos, es decir cuyos vínculos entre la expresión y el contenido tengan cabida en el dispositivo interpretativo cultural. Cabe resaltar, siguiendo a Lotman, que hay culturas que centran su creatividad en la expresión (el pensamiento ritual) y hay culturas que la centran en el contenido (el pensamiento simbolico): en el primer caso 
prevalece el conjunto de obras como realización de la cultura, en el segundo el mecanismo generativo, con el subsiguiente interés por el conjunto de reglas; en el primero, el deseo de ampliar los conocimientos, en el segundo, la apertura a nuevos modos de ver y de hacer, como aquéllos que establecen vínculos entre el arte y la ciencia, para dar un ejemplo.

8. LA ACCIÓN SIGNIFICANTE. La imagen artística despliega sus formas y contenidos desde una intención explícita o implícita: expresar en lo concreto de la materia el imaginario individual o colectivo. Desde adentro hacia fuera, " jugando ", a veces de manera dramática con los límites y las categorías, deja ver el proceso íntegro de la deconstrucción y la reconfiguración de la realidad o sorprende con visiones parciales de lo externo, de lo interno o de los nudos de la transición de los sentidos. El arte expresa, es decir interviene la realidad del entorno con imágenes-mundos, a las cuales instala en estructuras o contextos. En la interacción entre la imagen y su contexto de intervención se desafrolla el planteamiento comunicativo del arte.

La imagen comunica expresando. Tiene su propio modo de hacerlo, a través de la representación y la ejemplificación, términos lo suficientemente inquietantes para quien pensara que el arte es pura y a veces caótica pasión o, en el polo opuesto, mensaje contundente dirigido con voluntad y convicción, hacia los blancos de la realidad social, estética, cultural, psicológica o tantas otras visiones particulares qü̉ela hetéte bumaha suetet configurar.

\section{"Jorge Puccinelli Converso»}

La imagen representa. Es una representación de sí, de la instancia de la creación, desde lo subconsciente, la conciencia o la sobreconsciencia. Es también una representación del otro, tal como se encuentra integrado en el juego dialógico de la representación. Es una representación de lo referido, objeto o situación que experimentan una tematización aparente o subyacente. Es una representación del contexto, con todo lo que éste implica, cultura y parámetros situacionales, entre los cuales un papel muchas veces exagerado ha sido desempeñado por las normas artísticas. En este complejo fenómeno de representación se define la relación entre el arte y la realidad; entre el creador como sujeto productor de la imagen y el público, como sujeto intérprete de la imagen; entre el arte y el metatexto, es decir las pautas y normas que pretenden regir la manifestación; entre el arte y la cultura; entre el arte y el imaginario, como espacio intensamente energético, origen y fin de toda creación, punto nuclear del ciclo de las formas y las ideas, lugar de las figuras del pensamiento y lenguaje. 
La imagen ejemplifica. Es una ejemplificación de la reacción del ser humano ante el mundo de las significaciones que el mundo de las experiencias asume en una lectura individual o colectiva de sus determinaciones con respecto a la condición humana, desde marcos generales, como el antropológico o el filosófico, o específicos como el del género o del estilo. El carácter de ejemplificación encamina una vez más la atención hacia la relación del imaginario con la realidad experimentada por el individuo.

La imagen representa y ejemplifica, expresa y comunica, establece vinculos en varios niveles con lo de adentro y lo de afuera. Toda imagen lo hace, lo que nos lleva ante la preocupación por las diferencias entre lo artístico y lo no artístico, entre lo pragmático y lo no pragmático. Difícil linea divisoria, porque la imagen artistica puede asumir fines pragmáticos, en el arte político o el arte popular por ejemplo, mientras que la imagen pragmática puede asumir valores artísticos, como en la ilustración periodística, la caricatura o la fotografia documental. Tal vez sería cuestión de hablar de valores que se invierten en la imagen, como parte de su proceso generativo, desde el acto enunciativo y dentro de un marco de constante negociación colectiva con los hábitos culturales del consumo de imágenes del espacio de destino. Tal vez habria que affadir la cuestión de los valores asignados en el acto de recepción, como parte de una configuración situacional en la cual ocurre el contacto entre los dos imaginarios que comparten valores y referentes a la vez que se diferencian por valores y referentes. Los criterios de lo artístico plantean tantos problemas como los criterios de lo-original La creación auténticasse define a partir de limites y transgresiones y la heterogeneidad de concepto humano sobre un asunto $u$ otro encuentra una perfecta correlación en la heterogeneidad de la forma, procedente de una cultura de la imagen, generadora no sólo de una memoria colectiva sino también de una productividad basada en la alteración, la inversión, la adición, la sustracción, la modulación, la transposición y otros modos discursivos para crear lo propio a partir de lo ajeno.

Los modos de representación se basan en la voluntad de apropiación del mundo. Es esta unidad volitiva la que permite construir recorridos del sentido, pasando por las figuras del lenguaje, estrechamente relacionadas con las figuras del pensamiento. Su capacỉad de ejemplificación se centra en la relación del ser humano con su entorno, con una aguda conciencia de los limites, que llegan a formar su propia estructura matriz de los instintos, emociones e ideas del ser, en la cual el lenguaje desarrolla una estrategia de cambios y reconfiguraciones basada en la absorción de las figuras culturales que definen una época u otra. 
El lenguaje de la imagen artística se constituye entonces en una matriz de pensamiento, llamada por algunos " visión del mundo " donde convergen los instintos, las emociones, la conciencia. Se genera en este espacio del imaginario individual, que hipotéticamente pasa a formar parte del imaginario colectivo, afinidades, diferencias y desde luego estructuras comunes. Los sentidos se constituyen, se estructuran, se manifiestan. El semantismo de los términos y su orden enumerativo no son casuales. Cada uno marca una acción imbrincada en el proceso de la significación.

El lenguaje se constituye como vocación expresiva y comunicativa, como posición y reacción ante el entorno, como actualización de las numerosas posibilidades de lo visual, lo mental o lo material. Se constituyo por pensamiento y por práctica, entre la voluntad de libertad y la compleja determinación de la condición humana. Probablemente es la antropología cultural la que más alcances tenga al respecto, junto con la sicología y el psicoanálisis. Una zona ejemplar para enfocar el fenómeno es la constitución de las figuras simbólicas de la imagen, basadas en arquetipos culturales y la producción onírica. Desde este punto de vista, los mitos, las leyendas, los cuentos populares, la literatura y los sueños, comparten con la imagen artistica un sin fin de estructuras comunes, primarias y representativas para un pensamiento cósmico en el cual se ubica el pensamiento de sí del ser humano. Es el caso, por ejemplo, de figuras como el círculo, el cuadrado, la espiral, la cruz o de las formas de la expansión, del ritmo, de la organización e integración conceptual y formal, por medio de las cuales la imagen captura la dinámicạ delả tráns ormación, ordenanânola y asignándole sentidos que razonan sobre lo desconocido y loincontrolable, expandiendo el poder del ser a través del poder del imaginario. Podríamos llamar esta calidad activa del imagen una "visión ordenadora del mundo "que, desde luego, no se limita la caso citado del imaginario simbólico universal sino que desarrolla el mismo potencial en otras lecturas del mundo, donde el peso de las significaciones apunta a lo social o a lo político, a la cuestión del género o de las generaciones, o a lo estético, a través del cuestionamiento de las normas establecidas entre el contenido, la forma y la intención.

El lenguaje genera formas de ordenamiento que actualizan conceptos estructurantes del imaginario a la vez que generan recorridos específicos de la manifestación artística. Genera lecturas estéticas de la imagen interna, mental, en la cual pueden prevalecer opciones referenciales, esencialistas o simbólicas. Genera, desde las estructuras profundas del pensamiento, estructuras discursivas que van a manifestarse en el acto de la expresión. Genera ideas, perspectivas, opciones. Genera un recorrido enunciativo que se desarrolla en un campo 
valórico, en el cual la imagen define su identidad comunicativa, referencial, enunciativa, discursiva, apelativa, expresiva, dialógica. De este modo, la imagen asume su condición de texto y de discurso, se vuelve mundo, parte y todo al mismo tiempo.

El lenguaje estructura este mundo, basándose en su poder sobre el espacio y/o tiempo: surgen no sólo los puntos de vista sino también las estructuras " gramaticales " de la imagen, a las cuales podemos acercamos para delimitar una morfología , una semántica, una sintaxis y una pragmática de la imagen. Ello permitirá enfocar especificamente el fenómeno de la selección y combinación de elementos, de los sentidos asumidos y desarrollados, así como de los efectos de la imagen.

El lenguaje se manifiesta optando estéticamente, es decir con unas propuesta sistémica de relación entre contenido - forma - intención, en espacios modales diferentes: cerrados o abiertos, especializados o generales, públicos o privados. Queda patente la vocación de socialización, de "poner en común", a la vez que de autodefinirse dentro de lo otro.

Estas delimitaciones son sólo marcos para una reflexión analítica que pretende enfocar la imagen artística en el conjunto de las manifestaciones humanas como parte de la unidad y diversidad de los hechos y objetos de sentido que en éstas surgen. Son parte de un proyecto de semiótica de la imagen artística cuyos resultados estarán a disposición en la brevedad posible. 